\title{
Martensitic transformation in SUS 316LN austenitic stainless steel at RT
}

\author{
J. Manjanna, S. Kobayashi, Y. Kamada, S. Takahashi, H. Kikuchi \\ NDE and Science Research Center, Faculty of Engineering, Iwate University, Morioka 020- \\ 8551, Japan
}

\begin{abstract}
The results of high-accuracy magnetic measurements on SUS 316LN austenitic stainless steel compressively deformed at room-temperature (RT) are reported here. Even after the mild-deformation of $\sim 25 \%$ true-strain $\left(\varepsilon_{t}\right)$, the ferromagnetic phase ( $\alpha$-martensite) could be clearly observed which increased sharply on further deformation. The amount of $\alpha$ was very small $\left(0.18 \mathrm{vol} . \%\right.$ at $\left.\varepsilon_{t} \approx 60 \%\right)$ when compared to the reported data for other grades of austenitic steels such as 304, 304L, 316 and 316L.

The strain-induced $\alpha^{\prime}$-martensite is further studied by the magnetic hysteresis loops. The coercivity $\left(\mathrm{H}_{\mathrm{C}}\right)$ and remanence $\left(\mathrm{M}_{\mathrm{r}}\right)$ were analyzed by subtracting the paramagnetic contribution of the bulk austenite structure. While $\mathrm{H}_{\mathrm{C}}$ was found to decrease with $\alpha, \mathrm{M}_{\mathrm{r}}$ remained same $(\sim 67 \mathrm{emu} / \mathrm{g})$ when normalized to the volume fraction of $\alpha$. The decreasing $\mathrm{H}_{\mathrm{C}}$ with increasing $\alpha^{\prime}$ and/ or $\varepsilon_{t}$ is presumed to be due to the domain wall pinning at the grain boundaries when the cluster size exceeds the domain wall width.
\end{abstract}

Keywords: SUS 316LN; austenitic stainless steel; deformation at RT; martensitic transformation; magnetic hysteresis loops.

Author for correspondence

\section{J. Manjanna}

e-mail: jmanjanna@ rediffmail.com, Tel./Fax: +81-19-621-6350

\section{Introduction}

Austenitic stainless steels are extensively used in wide-spread industrial and technological applications where the combination of high corrosion resistance with high strength, toughness, and stiffness is needed. The different grades of austenitic steels used in the hostile environments (like the one prevailing in nuclear reactors - coolant water of high temperature 
and pressure) are SUS 304, 304L, 316, 316L and $316 \mathrm{LN}$. Type 316LN is of superior quality among 300 grade stainless steels. It is molybdenum bearing nitrogen-alloyed low carbon austenitic steel, which has high creep resistance, excellent formability, rupture and tensile strength at high temperature, corrosion and pitting resistance etc. Nitrogen added in the alloy helps in strengthening the solid-solution while the low carbon content makes it resistant to sensitization in short-term exposures. Comparatively, it is an alloy of choice to minimize any occasional but catastrophic failures (for e.g., environmentally assisted cracking). Hence SUS $316 \mathrm{LN}$ is being considered as the major fabrication alloy, at least, in the crucial components of the upcoming reactors.

It is well known that due to strain-induced deformation, the austenite crystal structure (fcc, $\gamma$ ) of stainless steel, which is paramagnetic at RT, is transformed to ferromagnetic martensite (bct, $\alpha^{\prime}$ ) [1-7]. This transformation can be related to deterioration of the material property for the safe operation of steel-based plants, because it can lead to cracks due to the hard and brittle nature of martensite phase, and associated micro-structural changes. Assessing the degradation of stainless steel by nondestructive magnetic method is of current interest [3-14] because magnetic properties are very sensitive to the changes in microstructures.

The extent of $\gamma \rightarrow \alpha$ transformation depends on the chemical composition of the alloy, deformation level and temperature. Extensive studies on $\gamma \rightarrow \alpha^{\prime}$ have been carried out using 304 austenitic steel by various deformations like compression [4], rolling reduction [5, 13, 14] and tensile testing $[3,7,9,15]$. The $\gamma \rightarrow \alpha$ was found to be accomplished relatively easily in 304 grades of stainless steel owing to its composition, especially when lower amounts of $\mathrm{Ni}(<10 \mathrm{wt} . \%)$ and/ or higher amounts of $\mathrm{Cr}(>18 \mathrm{wt} . \%)$ are present. This is because alloying elements like $\mathrm{Ni}, \mathrm{Mn}, \mathrm{N}$ and $\mathrm{Cu}$ considerably stabilize the austenite structure while the $\mathrm{Cr}$ promotes $\alpha^{\prime}$ structure. There are few studies on the deformation induced $\alpha^{\prime}$ in 316 stainless steel [15-20]. For instance, tensile testing [15] and selective generation of local ferromagnetism by nanoindentation [19] have been reported for the type 316 stainless steel. In the case of 316L stainless steel, severe deformation such as cold-drawing of wire [17] has produced significant amount of $\alpha$ as shown by X-ray diffraction (XRD) and transmission electron microscopy (TEM). Similarly, ball-milling of 316L stainless steel powder also produced $\alpha$ as determined by XRD and Mössbauer spectroscopy [20]. Miller et al. [12] have used magnetic force microscopy to image strain-induced $\alpha$ resulting from fatigue crack growth in a 316L stainless steel. On the other hand, Botshekan et al., [18] have found no $\alpha$ in $316 \mathrm{LN}$ deformed (tensile) up to rupture at RT, unlike when deformed in low temperature of 
$77 \mathrm{~K}$. Based on these studies, $\gamma \rightarrow \alpha^{\prime}$ in different grades of austenitic stainless steels can be shown, broadly, in the decreasing order as $304>304 \mathrm{~L}>316>316 \mathrm{~L}>316 \mathrm{LN}$ when deformed to the same extent at a given temperature.

It is generally believed that in $316 \mathrm{LN}$ stainless steels, such $\gamma \rightarrow \alpha^{\prime}$ transformation is negligible when deformed at RT. However, it is of interest to see if there is any fractional amount of $\alpha$ when the so-called stable steel, SUS $316 \mathrm{LN}$ is deformed. The results of highaccuracy magnetic measurements on SUS 316LN compressively deformed at RT are reported here. It was found that the ferromagnetic fraction could be clearly observed even after the mild-deformation of $\sim 25 \%$ true-strain. Nevertheless, the amount of $\alpha$ was very low $(<0.2$ vol\%), which is much less than that occurs in other grades of austenitic steels when deformed to same extent.

\section{Experimental}

The chemical composition of the SUS 316LN austenitic stainless steel used in this study is given in Table 1. As-received alloy (from The Japan Steel Works Ltd.) was in the form of 1 $\mathrm{cm}$ thick disc sliced from a rod with a diameter of $\sim 8 \mathrm{~cm}$. Then, it was cut to $3 \times 3 \times 2 \mathrm{~mm}$ size using electric discharge wire-cutting machine. The samples were solution annealed at 1050 ${ }^{0} \mathrm{C}$ for $80 \mathrm{~min}$ in vacuum and then water quenched. Before compression, the samples were electro-polished using a mixture of ethanol and perchloric acid in the 9:1 volume ratio and then cleaned with ethonal in ultrasonic bath. Samples were compressed at RT (at a strain rate of $0.5 \mathrm{~mm} / \mathrm{min}$ ) by using a Shimadzu Autograph Type SFL-250kN AG Instron testing machine. The different levels of compression up to $61.4 \%$ of true-strain $\left(\varepsilon_{t}\right)$ were obtained. Magnetization $(M)$ was measured at $300 \mathrm{~K}$ by using a superconducting quantum interference device magnetometer, Quantum Design MPMS-XL. The applied field $(H)$ was perpendicular to the axis of compression.

\section{Results and Discussion}

\section{Saturation magnetization or $\alpha$-martensite versus $\mathcal{E}_{t}$}

As can be seen in Fig. 1, the initial magnetization curve of un-deformed $\left(\varepsilon_{t}=0\right)$ sample is linear in the entire field range showing the typical paramagnetic behavior due to pure austenite phase. Such a linear behavior was seen for $7.5 \%$ and $15 \%$ compressed samples also (not plotted here). However, after compressing to $\varepsilon_{t}>25 \%$, magnetization increased sharply 
in the lower field region, and thereafter gradually increased with applied field. The first part of magnetization curve can be attributed to the strain-induced ferromagnetic phase $(\alpha)$. This ferromagnetic component become magnetically saturated soon after the field was applied, and the saturation field varied from 0.5 to $5 \mathrm{kOe}$ depending on its volume fraction.

Fig. 2 shows the derivative plots for the deformed samples. In corroboration with the data in Fig. 1, the increasing derivative maxima can be clearly seen after $\varepsilon_{t} \approx 25 \%$.

It is well know that, only $\alpha$ structure contributes to ferromagnetic part, due to straininduced $\gamma \rightarrow \alpha^{\prime}$ transformation of austenitic steels at RT and above [3-18]. In order to evaluate the amount of $\alpha$, the saturation magnetization $\left(M_{s}\right)$ was obtained from the plots in Fig. 1 corresponding to intercept of the linear extrapolation from the high-field region to ordinate, and plotted in Fig. 3. The magnetization of deformed samples after subtracting the paramagnetic contribution (equivalent to magnetization of un-deformed sample) is shown in the inset of Fig. 3, and the $M_{\mathrm{s}}$ obtained from these plots is same as that from Fig.1. $M_{s}$ of $100 \%$ martensite transformed 304 grade steel is reported to be $\sim 153 \mathrm{emu} / \mathrm{g}$ [21] while it is $\sim 143 \mathrm{emu} / \mathrm{g}$ for 316LN grade steel [18]. Accordingly, Fig. 3 also shows the amount of $\alpha$ which increased sharply when $\varepsilon_{t}>25 \%$. However, the amount of $\alpha$ obtained here was very small, 0.18 vol.\% at $\varepsilon_{t} \approx 61.4 \%$. This suggests that the $\gamma \rightarrow \alpha$ transformation is highly hindered in SUS 316 LN steels unlike in the other grades such as 304, 304L, 316 and 316L austenitic steels [3-18].

During plastic deformation, the martensitic transformation takes place by shearing of the lattice like generation of twins or stacking faults. Due to plastic deformation, the dislocation density increased and, in consequence, also the stacking fault density. In fcc lattices, stacking faults (SF) are of hexagonal symmetry, like $\varepsilon$-martensite (hcp); $n$ stacking faults can form a hexagonal $\mathcal{E}$-martensite crystal. The transformation from austenitic to $\alpha$-martensite was thus believed to follow [22, 23], $\gamma \rightarrow \mathrm{SF} \rightarrow \mathrm{nSF} \rightarrow \varepsilon \rightarrow \alpha^{\prime}$.

The approximate amount of $\alpha^{\prime}$ in 300 grades of austenitic stainless steels when deformed to the same extent, $\mathcal{E}_{\mathrm{t}} \approx 65 \%$ at $300 \mathrm{~K}$, could be shown in the order: $304(90 \%)>304 \mathrm{~L} \mathrm{(30 \% )}$ $>316(3 \%)>316 \mathrm{~L}(2 \%)>>316 \mathrm{LN}(0.2 \%)$-value in parenthesis is the amount of $\alpha$ in vol\%. The large difference in $\gamma \rightarrow \alpha^{\prime}$ transformation especially between 316L and $316 \mathrm{LN}$ is usually attributed the alloying element nitrogen. Nitrogen in austenitic solid solution is an enormously useful element with respect to austenite stability, corrosion resistance and mechanical properties. The superior properties of $316 \mathrm{LN}$ such as better resistance to, fatigue crack growth, irradiation embrittlement and high temperature oxidation, have been ascribed 
to the presence of nitrogen. During the strain-induced deformation, nitrogen is known to make an obstacle for the movement of dislocations. The role of nitrogen seems to be more complex, decrease in stacking fault energy (SFE) and other mechanisms (short-range order effects), which can favor planar slip of dislocations or, in other words, to reduce the tendency for cross slip and avoid a tri-dimensional cellular structure [23, 24]. Vogt et al. have reported [24] the TEM observation of $316 \mathrm{~L}$ and $316 \mathrm{LN}$ after low-cycle fatigue test at $300 \mathrm{~K}$. Accordingly, in 316L, the dislocations are entangled and arranged in uncondenced and poorly defined walls. Increase in strain amplitude $\left(\Delta \varepsilon_{\mathrm{t}}\right)$ results in a more homogeneous structures having well formed misoriented cells. On the other hand, in $316 \mathrm{LN}$, the dislocations are quite homogeneously distributed, often confined in their [111] slip planes, and sometimes they tend to form planar bands. At higher $\Delta \varepsilon_{\mathrm{t}}$, the dislocation walls are formed but are not very condensed and are less often misoriented than with 316L. Further, for comparison, the $\alpha$ formed (due to low-cycle fatigue test, $\Delta \varepsilon_{\mathrm{t}}=2.5 \%$ ) at $77 \mathrm{~K}$ was $\sim 66 \mathrm{vol} \%$ in $316 \mathrm{~L}$ while it is only $\sim 4 \mathrm{vol} \%$ in $316 \mathrm{LN}$. The occurrence of a difference in the mechanism of $\gamma \rightarrow \alpha$ transformation at low temperature presumably originate by the effect of nitrogen at low temperature through a decrease in SFE and a reduced mobility of the dislocations, martensite transforms directly from austenite.

\section{Hysteresis loops - coercivity $\left(H_{C}\right)$ and remanence $\left(M_{r}\right)$}

To demonstrate the ferromagnetic behavior further, the hysteresis loops were measured in the field range of $\pm 30 \mathrm{kOe}$. Fig. 4 shows the enlarged view of the as-measured loops of deformed samples in comparison with un-deformed sample. It is evident that the loops are bulged as the $\alpha$-martensite was increased with $\mathcal{E}_{t}$. Inset in Fig 4 shows the full view of loops of un-deformed and maximum deformed sample, as a typical case.

In order to estimate the actual behavior of $\mathrm{Hc}$ and $\mathrm{M}_{\mathrm{r}}$ versus $\alpha$ fraction and/ or $\varepsilon_{t}$, it is essential to subtract the paramagnetic contribution especially when very small amount of $\alpha$ was formed (as in the present study). Accordingly, Fig. 5 shows the select view of the loops after subtracting the paramagnetic contribution (equivalent to the un-deformed sample), and

normalized to the corresponding amount of $\alpha$. As shown in the inset of Fig $5, \mathrm{H}_{\mathrm{C}}$ was found to decrease with increasing $\alpha$. On the other hand, $\mathrm{M}_{\mathrm{r}}$ remained more or less same at $\sim 67$ $\mathrm{emu} / \mathrm{g}$ suggesting that $\mathrm{M}_{\mathrm{r}}$ is independent of the ferromagnetic volume fraction.

The variation of $\mathrm{H}_{\mathrm{C}}$ as a function of the volume fraction of $\alpha^{\prime}$ and/or strain rate has been reported in many of the studies $[7,13,14,25]$, but the decreasing or increasing trend of $\mathrm{H}_{\mathrm{C}}$ is 
not consistent. For instance, $\mathrm{H}_{\mathrm{C}}$ was reported to decrease continuously with volume fraction of $\alpha$ in SUS 304 after tensile testing [7], cold-rolled AISI 304L steel [13], and in the mechanically milled 304 stainless steel powder [25]. On the other hand, $\mathrm{H}_{\mathrm{C}}$ increased with $\alpha$ in AISI 304 wherein the intermediate amount of martensite was formed [14]. Further, it is not clear in those studies weather the paramagnetic contribution is subtracted or not. Hence, the results obtained from Fig. 5 here could not be compared directly with the previous reports. Nevertheless, the decreasing or increasing trend of $\mathrm{H}_{\mathrm{C}}$ may be attributed to the different microstructural interactions of $\alpha$, based on its volume fraction $[14,26]$.

As revealed in the study of Mumtaz et al. [4], at about 0.12 vol.\% of $\alpha$, the size was in the order of nanometer scale $(<100 \mathrm{~nm})$. Thus, it is presumed here that the isolate $\alpha$ particles (nano clusters or grains equivalent to the thickness of domain wall) are distributed wide apart that the intercluster interaction is negligible while intracluster interaction is dominant. On increasing the amount of strain, the clusters size and also number density are expected to increase. When the cluster size exceeds the domain wall width, the magnetization process is determined by domain wall pinning at the grain boundaries. Under such situation, Hc is inversely proportional to the grain size $[4,26,27]$. Our experimental data of Hc versus truestain (Fig 5 inset) indeed show this behavior. On the other hand, random anisotropy model $[14,26,27]$ explains the decreasing $\mathrm{H}_{\mathrm{C}}$ based on intercluster exchange interations (when significant amount of $\alpha$ was formed) and increasing $\mathrm{H}_{\mathrm{C}}$ based on intracluster exchange interations (when intermediate amount of $\alpha^{\prime}$ was formed). However, in the present study, total amount of $\alpha^{\prime}$ is too small to invoke such exchange interaction. Nevertheless, more detailed studies are needed to support the microstructural information of $\alpha$, and will be considered in our future studies.

\section{Conclusion}

The ferromagnetic fraction in SUS 316LN austenitic stainless steel was clearly seen when deformed (compressively) at RT, due to $\gamma \rightarrow \alpha^{\prime}$ transformation. However, such a transformation was considerably hindered, and the $\alpha^{\prime}$ was $<0.2$ vol.\% when deformed to $\sim 60 \%$ true-strain. $\mathrm{H}_{\mathrm{C}}$ and $\mathrm{M}_{\mathrm{r}}$ were analyzed by subtracting the paramagnetic contribution of the bulk austenite structure. While $\mathrm{H}_{\mathrm{C}}$ was found to decrease with $\alpha, \mathrm{M}_{\mathrm{r}}$ remained same $(\sim 67$ $\mathrm{emu} / \mathrm{g}$ ) when normalized to the volume fraction of $\alpha^{\prime}$. The decreasing $\mathrm{H}_{\mathrm{C}}$ with increasing $\alpha^{\prime}$ and/ or true-strain is presumed to be due to the domain wall pinning at the grain boundaries 
when the cluster size exceeds the domain wall width. We believe that these results can serve as the experimental evidence for the small fraction of $\alpha$ formation in SUS $316 \mathrm{LN}$, which is less common alloy to study by magnetic method when deformed at RT, unlike low temperature deformations.

\section{References}

1. Hecker SS, Stout MG, Staudhammer KP, Smith JL (1982) Metall Trans A 13A: 619

2. Nagy E, Mertinger V, Tranta F, Sólyom J (2004) Mater Sci Eng A 378: 308

3. Takahashi S, Echigoya J, Ueda T, Li X, Hatafuku, H (2001) J Mater Proc Tech 108: 213

4. Mumtaz K, Takahashi S, Echigoya J, Zhang L-F, Kamada Y, Sato M (2003) J Mater Sci 38: 3037

5. Mumtaz K, Takahashi S, Echigoya J, Kamada Y, Zhang L-F, Kikuchi H, Ara K, Sato M (2004) J Mater Sci 39: 1997

6. Zhang L, Kamada Y, Kikuchi H, Mumtaz K, Ara K, Takahashi S, Sato M, Tsukada T (2004) J Magn Magn Mater 271: 402

7. Zhang L, Takahashi S, Kamada Y, Kikuchi H, Ara K, Sato M, Tsukada T (2005) J Mater Sci 40: 2709

8. Kamada Y, Mikami T, Takahashi S, Kikuchi H, Kobayashi S, Ara K (2007) J Magn Magn Mater 310: 2856

9. O'Sullivan D, Cotterell M, Meszaros I (2004) NDT \& E Int 37(4): 265

10. Vértesy G, Tomáš I, Meszáros I (2007) J Magn Magn Mater 310: 76

11. Park DG, Kim DW, Hong JH, Timofeev VP, Kim CG (2000) J Magn Magn Mater 215216: 785

12. Miller A, Estrin Y, Hu XZ (2002) Scripta Mater 47: 441

13. Tavares SSM, Da Silva MR, Neto JM, Miraglia S, Fruchart D (2002) J Magn Magn Mater 242-245: 1391 
14. Mitra A, Srivastava PK, De PK, Bhattacharya DK, Jiles DC (2004) Metall Mater Trans A 35A: 559

15. Varma SK, Kalyanam J, Murr LE, Srinivas V (1994) J Mater Sci Lett 13: 107

16. Srinivas V, Varma SK, Murr LE (1995) Metall Mater Trans A 26A: 661

17. Wang HS, Yang JR, Bhadeshia HKDH (2005) Mater Sci Technol 21(11): 1323

18. Botshekan M, Degallaix S, Desplanques Y, Polak J (1998) Fatigue Fract Engng Mater Struct 21: 651

19. Sort J, Concustell A, Menendez E, Surinach S, Baro MD, Farran J, Nogues J (2006) Appl Phys Lett 89: 032509

20. Szymańska A, Oleszak D, Grabias A, Rosinski M, Sikorski K, Kazior J, Michalski A, Kurzydlowski KJ (2004) Rev Adv Mater Sci 8: 143

21. Stearns MB (1976) Phys Rev B 13: 1183

22. Hübner W (2001) Trib Int 34: 231

23. Schramm RE, Reed RP (1975) Metall Trans A 6: 1345

24. Vogt J-B, Foct J, Regnard C, Robert G, Dhers J (1991) Met Mater Trans A22(10): 2385

25. Ding J, Huang H, Mccormick PG, Street R (1995) J Magn Magn Mater 139: 109

26. Herzer G (1990) IEEE Trans Magn 26: 1397

27. Alben R, Becker, JJ, Chi MC (1978) J Appl Phys 49(3): 1653 


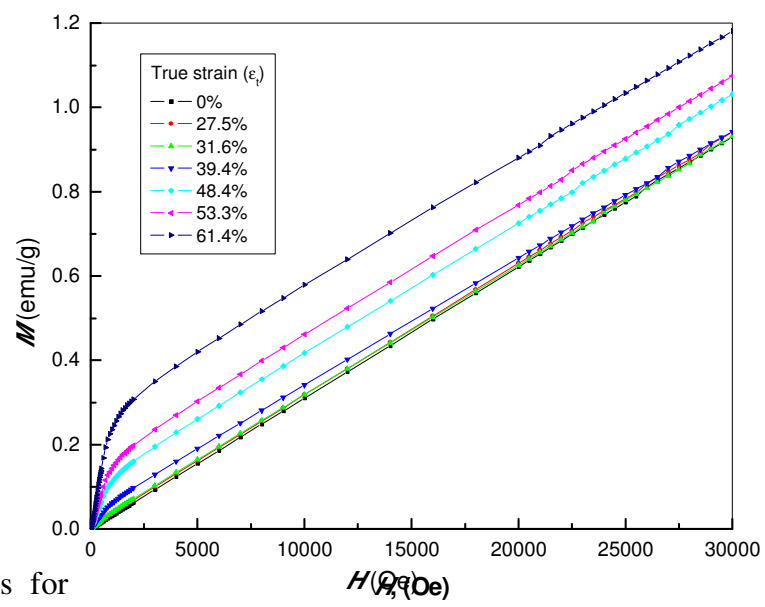

Fig. 1 Initial magnetization curves for different levels of compression measured at $300 \mathrm{~K}$.

Fig. 2 Derivative of magnetization to magnetic field as a function of applied

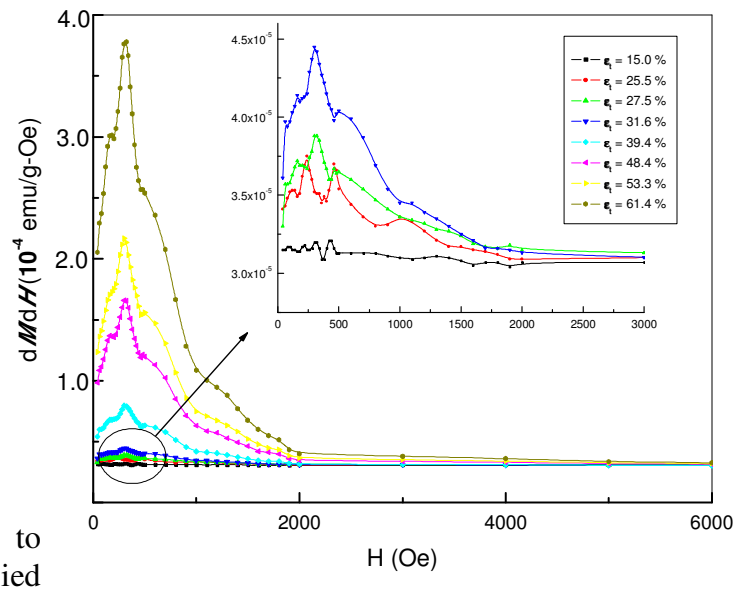
magnetic field for different levels of compression.

Fig. 3 Saturation magnetization and volume percent of $\alpha$-martensite as a function of true-strain. Inset:

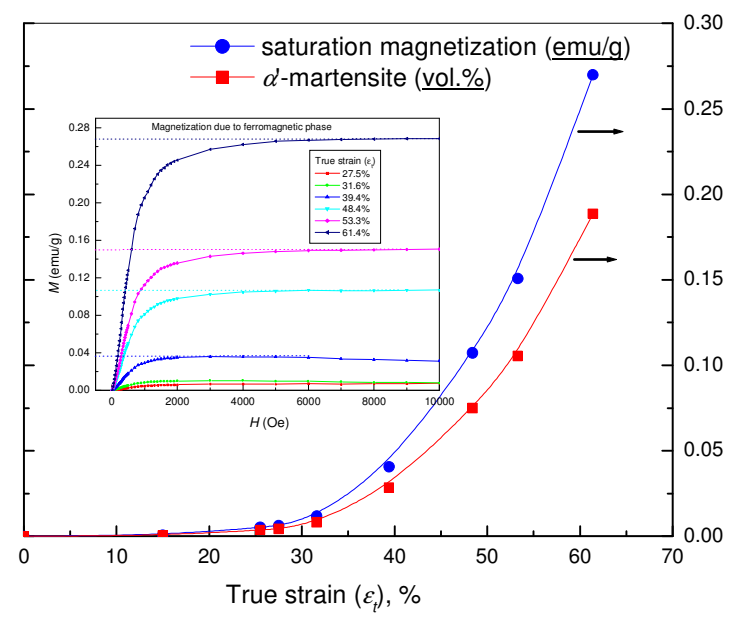
magnetization plots after subtracting paramagnetic contribution. 
Fig. 4 Enlarged view of the as-measured $\mathrm{M}-\mathrm{H}$ loops for different levels of compression. Inset is the full-view of un-

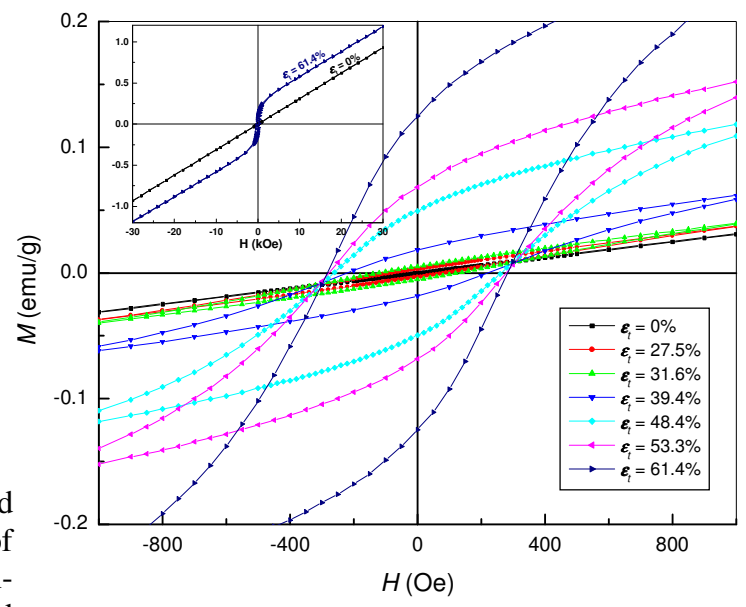
sample.

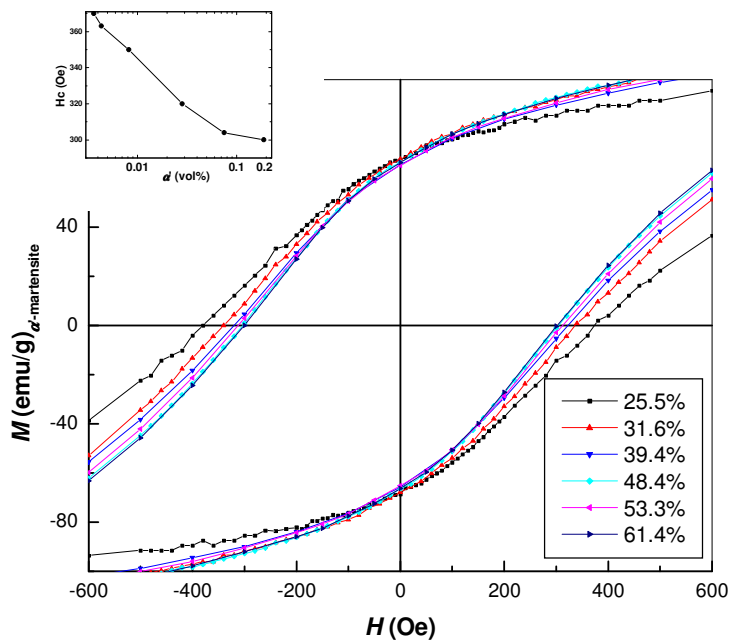

Fig. $5 \mathrm{M}-\mathrm{H}$ loops after subtracting the paramagnetic contribution, and normalized to the corresponding weight fraction of $\alpha$-martensite. Inset (middle) is the coercivity $\left(\mathrm{H}_{\mathrm{c}}\right)$ as a function of $\alpha$-martensite. 